\title{
ELECTROCONDUCTIVE FOILS BASED ON BIODEGRADABLE POLYMERS USED FOR FOOD PRESERVATION
}

\author{
ANDRZEJ IWAŃCZUK and MARTYNA WALKÓW \\ Wroclaw University of Science and Technology, 9, Grunwaldzki Str., 50-370 Wroctaw, Poland \\ \Corresponding author: Andrzej Iwańczuk, andrzej.iwanczuk@pwr.edu.pl \\ Dedicated to the $70^{\text {th }}$ anniversary of the Department of Pulp and Paper, \\ "Cristofor Simionescu" Faculty of Chemical Engineering and Environmental Protection, \\ "Gheorghe Asachi" Technical University of Iasi
}

\begin{abstract}
The aim of this work was to produce a biodegradable film based on a Mater-Bi matrix and to determine its strength and electrical properties. As matrix, two biodegradable materials, Mater-Bi EF51L and HF03A2, were used, while conductive carbon black (CB) was used as filler, which affects the formation of electroconductive paths in the material. Eight different composites were made, so that each material contained $0,1,2$ and $4 \% \mathrm{CB}$, respectively. In order to evaluate the influence of the filler content on the properties of the materials, tensile strength, electrical conductivity and fracture surface tests were performed. It was found that Mater-Bi biodegradable materials, in combination with carbon black, are very good conductors, and an increase in carbon black content affects the strength properties of the end materials. The obtained results have evidenced the superiority of the composites with the lowest carbon black content.
\end{abstract}

Keywords: biocomposites, starch, material testing, mechanical properties, electroconductivity

\section{INTRODUCTION}

Today, more than half of the packaging products on the market are made of plastic. Their popularity is due to their weight, which is only $17 \%$ of the weight of all packaging products. Light weight packaging reduces the demand for trucks, which in turn results in lower fuel consumption, emissions and transport costs, and less waste is generated. ${ }^{1}$ The development of new materials based on renewable resources, as an alternative to traditional polymer composite materials, has become an important research topic due to customers' rights and market requirements, as well as environmental legislation. ${ }^{1}$

The consumption of biopolymers increases every year. This increase is caused by the fact that they are widely used for food products, as well as because of the significant burden produced by non-biodegradable materials on the environment. Currently, bioplastics account for about $1 \%$ of the world plastics production. ${ }^{2}$

In the food industry, plastic packaging is used to protect against contamination and bacteria. Closed packaging provides additional security, and the transparent color allows checking the food without having to touch it. Packaging also contributes to extending product validity. As a result, the amount of food waste and the use of preservatives are reduced, while the nutritional values and taste are preserved. ${ }^{3}$

The most commonly used plastic films are not biodegradable. Currently, it is assumed that about $10 \%$ biodegradable plastics may be used in the production of packaging. In the future, biodegradable films are intended to gradually replace the plastic packaging films used so far. ${ }^{2}$

Among biodegradable plastics, mixtures based on starch and PLA are the most popular, ${ }^{2}$ due to the high of availability these products. The wide family of innovative biodegradable plastics produced from natural agricultural products, such as starch, cellulose, vegetable oils and their derivatives, is called Mater-Bi. The production of Mater-Bi uses various types of plant ingredients, which include cellulose, glycerin and unmodified starch.

Corn starch is the most popular biodegradable polysaccharide that can be synthesized by numerous plants. It is a semicrystalline polymer 
composed of linear amylose and highly branched amylopectin and is extracted from grains. Commercial starch-based blends have been developed.

Thus, Mater-Bi polymer blends containing starch have a diverse structure, because starch forms complexes with other polymeric components or is distinguished by its fine, dispersed morphology. This makes the products extremely hard.

In the Mater-Bi family, there are also species that do not contain starch, and biodegradable polymers that are produced from raw materials of fossil origin or from renewable sources. The use of fossil raw materials is only possible when renewable raw materials are not available at industrial level.

Bioplastics are materials with properties similar to those of classic polymer plastics, but at the same time, they are biodegradable and can be used in composting processes in accordance with the European standard EN 13432: 2002. Due to these properties, products made from Mater-Bi allow the optimization of wastes collection and the management of this processes, as well as the reduction of their impact on the environment. Wastes from Mater-Bi are fully biodegradable and suitable for composting and anaerobic digestion. Some types guarantee biodegradation in home compost and soil, and even in the marine environment.

Due to the multitude of Mater-Bi species, their properties differ significantly. The mechanical properties of the products range from those with low Young's modulus and high ductility to rigid and fragile products. Their color oscillates from milky to transparent. However, all grades can be processed by, for example, extrusion, blow molding, injection molding or compression. ${ }^{4}$

Polymeric conductive polymer composites consist of a polymer matrix, which performs an insulating function, and an electrically conductive filler. ${ }^{5}$ They are characterized by exceptional properties, such as low weight, easy processing, corrosion resistance and forming ability. As a result, they have been used, among others, in cables as a shielding layer, devices particularly sensitive to electromagnetic fields, industrial pipes and hoses, as well as in medicine, automotive industry, ${ }^{7}$ electronics ${ }^{8}$ and food industry. ${ }^{9}$

There are many electrically conductive fillers on the market. They can be used as shields, antistatic and metal conductors. The most popular fillers are $\mathrm{CB}$, graphite and powders or metal fibers, and are used to create a conductive path that is based on the percolation phenomenon. ${ }^{10}$

The main objective of this work was to evaluate the potential of two kinds of starch-based thermoplastic as matrix for new electroconductive materials.

\section{EXPERIMENTAL}

\section{Materials}

Mater-Bi EF51L, with specific gravity of 1.26 $\mathrm{g} / \mathrm{cm}^{3}$ from Novamont S.p.A., Italy, and Mater-Bi HF03A2, with specific gravity of $1.26 \mathrm{~g} / \mathrm{cm}^{3}$ from Novamont S.p.A., Italy, were used as matrix. Electroconductive carbon black - Ketjenblack EC300J, with apparent bulk density of $125-145 \mathrm{~kg} / \mathrm{m}^{3}$, pore volume (DBP) of 310-345 mL/100 g, from Akzonobel, Netherlands, was used as filler.

\section{Composite preparation}

The materials did not require drying before processing. Master batches were first prepared through a melt blend in a weight ratio of $80 / 20$. They were mixed for 6 minutes at $170{ }^{\circ} \mathrm{C}$. Composites were made using a Haake Rheomex CTW 100 twin screw extruder, in ratios of 99/1, 98/2 and 96/4, at temperatures between $155-165{ }^{\circ} \mathrm{C}$ and rotation speed of 10.5-16.5 rpm, depending on the materials used.

The films were prepared using a LabTech LP-20B hydraulic press at $170-190{ }^{\circ} \mathrm{C}$, depending on the matrices used. Samples for tensile testing and percolation threshold were cut from the prepared foil. Sample composition and notation are presented in Table 1.

\section{Test methods}

All mechanical tests took place at $50 \%$ relative humidity and $23{ }^{\circ} \mathrm{C}$. The specimens were conditioned under the same conditions for $24 \mathrm{~h}$ before testing. The strength properties of the composites were determined using a Lloyd LR10K machine. The stretching of the samples took place at a speed of $10 \mathrm{~mm} / \mathrm{min}$.

Sample fractures were visualized using a VEGA3 Tescan scanning electron microscope (SEM). Gold was sprayed on their surface during $60 \mathrm{~s}$. Then, the fracture surfaces were analyzed under a microscope, in vacuum at a pressure between $10^{-4}-10^{-5} \mathrm{~Pa}$. SEM images with magnifications of 2200x and 1800x were taken.

Gold electrodes were applied to the samples with a view of determining the percolation threshold. The current flow was determined by a Keithley 6512 electrometer from Keithley Instruments, and the power source was a GPR-30H100 high-voltage power supply (GW-Instek). 


\section{RESULTS AND DISCUSSION \\ Mechanical properties}

The mechanical properties, such as Young's modulus, tensile strength and elongation at break, as well as stress at maximum load, of the composite materials were evaluated. The measurements showed that even a content of $1 \%$ carbon black by weight added to the matrix of Mater-Bi EF51L and HF03A2, respectively, resulted in a sharp drop in resistance. Carbon black was very well dispersed in the material (see the discussion of SEM below), allowing the formation of continuous conductive paths in them.

The increase of the filler content in the composites, in the case of both types of Mater-Bi, did not cause significant changes in the appearance of the stretching diagrams in relation to the matrix itself, while it affects the values of stress and deformation. Among other things, it causes an increase in Young's modulus (Figs. 12). This is mainly connected to $\mathrm{CB}$ particles blocking the polymer orientation process during the elongation process.

Table 1

Notations and compositions of the studied composites

\begin{tabular}{lcc}
\hline Notation & Matrix (wt\%) & Filler content (wt\%) \\
\hline Mater-Bi EF51L & 100 & 0 \\
Mater-Bi EF51L + 1\% CB & 99 & 1 \\
Mater-Bi EF51L + 2\% CB & 98 & 2 \\
Mater-Bi EF51L + 4\% CB & 96 & 4 \\
Mater-Bi HF03A2 & 100 & 0 \\
Mater-Bi HF03A2 + 1\% CB & 99 & 1 \\
Mater-Bi HF03A2 + 2\% CB & 98 & 2 \\
Mater-Bi HF03A2 + 4\% CB & 96 & 4 \\
\hline
\end{tabular}

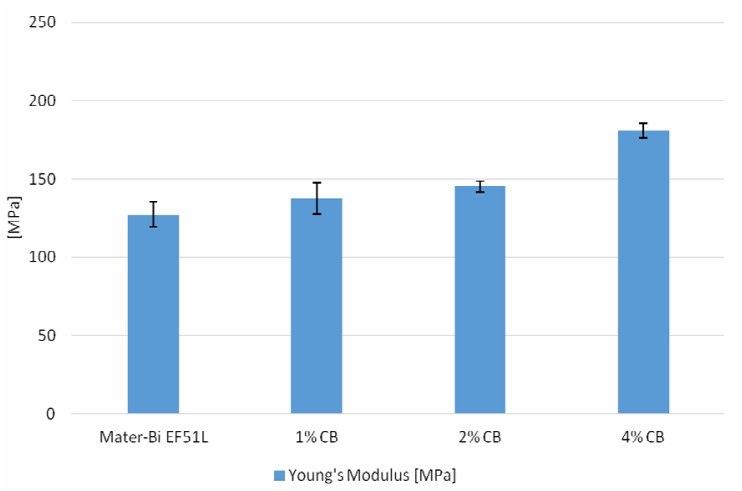

Figure 1: Evolution of Young's modulus of Mater-Bi EF51L composites as a function of $\mathrm{CB}$ content

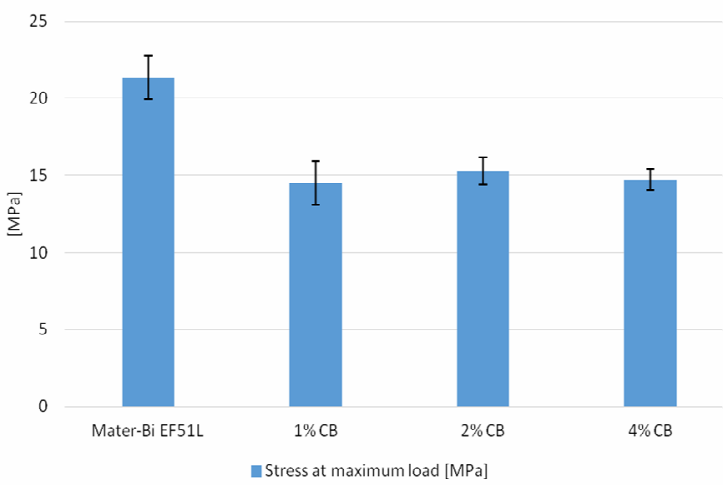

Figure 3: Evolution of stress at maximum load of Mater-Bi EF51L composites as a function of CB content

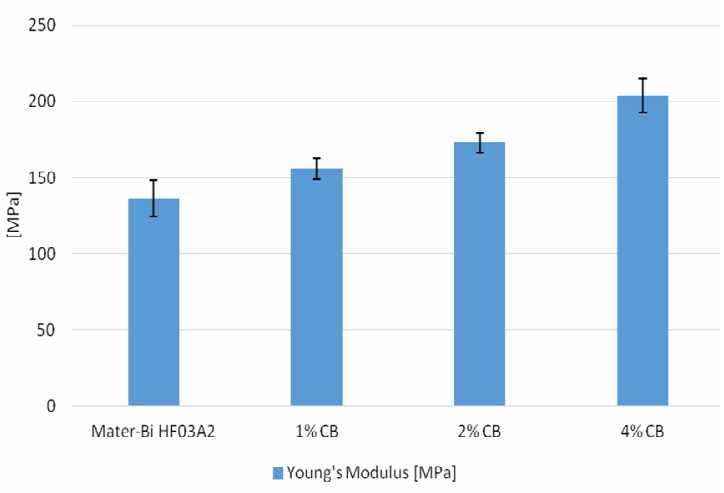

Figure 2: Evolution of Young's modulus of Mater-Bi HF03A2 composites as a function of $\mathrm{CB}$ content

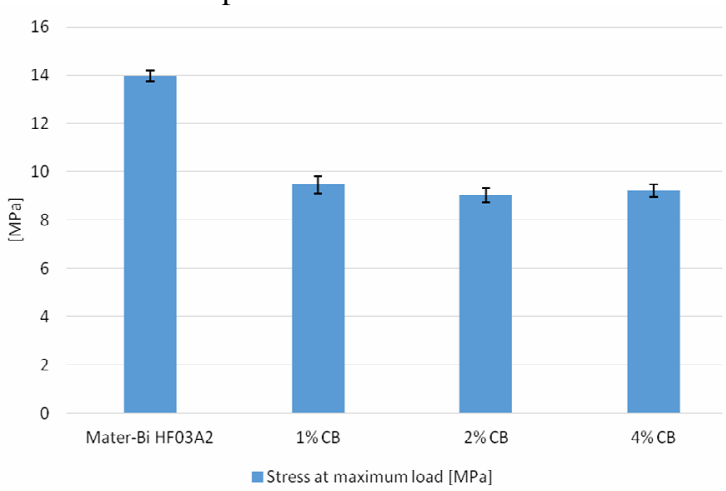

Figure 4: Evolution of stress at maximum load of MaterBi HF03A2 composites as a function of CB content 


\section{ANDRZEJ IWAŃCZUK and MARTYNA WALKÓW}

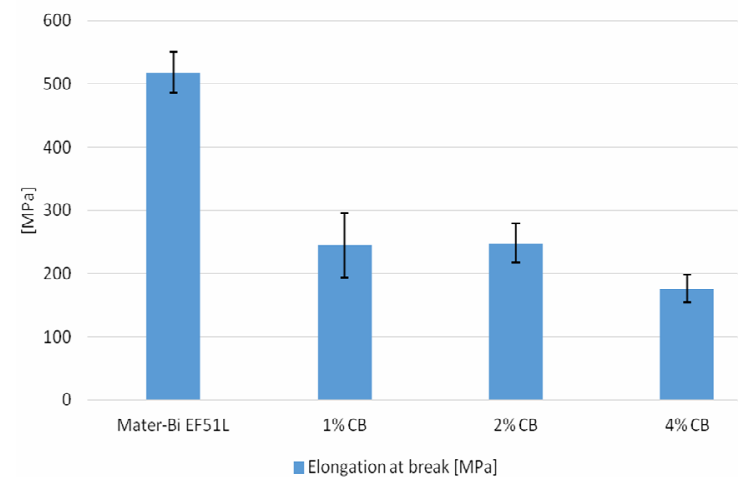

Figure 5: Evolution of elongation at break of Mater-Bi EF51L composites as a function of CB content

Relative elongation mainly depends on the type of the matrix and it is definitely greater for Mater-Bi EF51L. The presence of carbon black in both materials reduces their relative elongation and also increases the stiffness of the composites (Figs. 5-6). The material becomes less plastic, cracking at smaller elongations. Also, the presence of carbon black reduces the stress at maximum load of the obtained materials, however, increasing its amount does not cause further changes to this parameter.

\section{SEM}

The SEM technique was used to evidence the dispersion of the filler into the polymer matrix. Thus, in the composites comprising $2 \%$ and $4 \%$
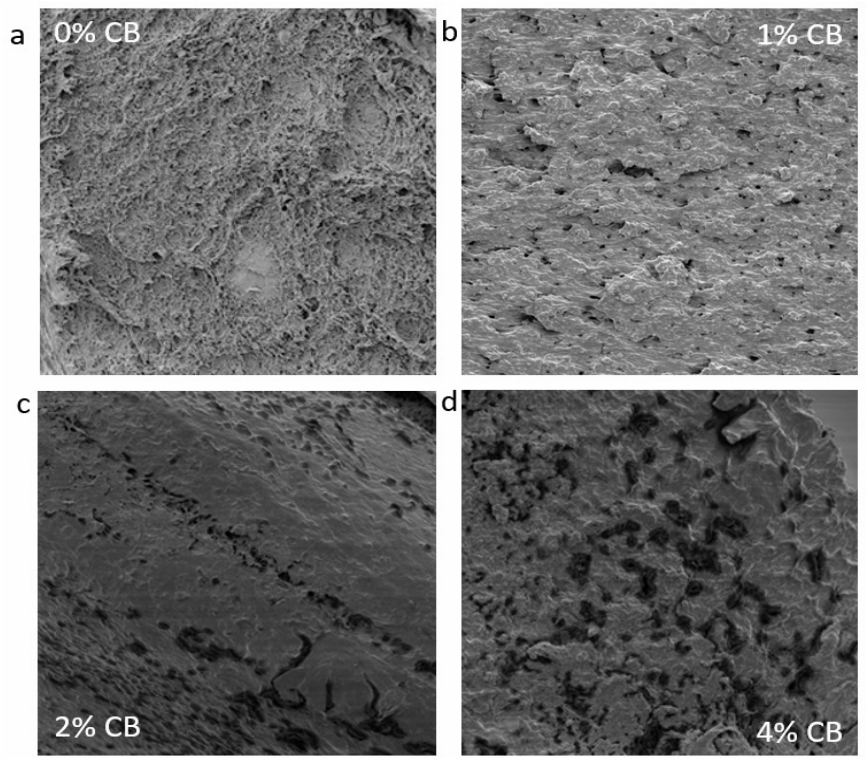

Figure 7: SEM MAG: 2.2kx images of Mater-Bi EF51L morphology with carbon black 0\% (a), 1\% (b), $2 \%$ (c) and $4 \%(\mathrm{~d})$ content 


\section{Percolation threshold}

The percolation threshold represents the minimum contents of filler necessary to construct the electrical path in a composite material. It seems that conductive polymer composites developed by conventional melt blending present poor electrical properties at low filler content. ${ }^{11}$ According to other authors, ${ }^{12}$ the segregated structure in conductive polymer composites can effectively reduce the electrical percolation threshold and improve electrical conductivity.

The electrical conductivities of the Mater-Bi EF51L and Mater-Bi HF03A2 composites with various $(1-4 \%)$ carbon black concentrations are shown in Table 2.

Table 2

Comparison of electrical properties of the composite materials

\begin{tabular}{lc}
\hline Composite & Conductivity at $20{ }^{\circ} \mathrm{C}(\mathrm{S} / \mathrm{cm})$ \\
\hline Mater-Bi EF51L & $2.37 * 10^{-11}$ \\
Mater-Bi EF51L + 1\% CB & $1.74 * 10^{-2}$ \\
Mater-Bi EF51L + 2\% CB & $1.74 * 10^{-2}$ \\
Mater-Bi EF51L + 4\% CB & $1.74 * 10^{-2}$ \\
Mater-Bi HF03A2 & $1.16^{*} 10^{-11}$ \\
Mater-Bi HF03A2 + 1\% CB & $1.74 * 10^{-2}$ \\
Mater-Bi HF03A2 + 2\% CB & $1.74 * 10^{-2}$ \\
Mater-Bi HF03A2 + 4\% CB & $1.74 * 10^{-2}$ \\
\hline
\end{tabular}

According to the measurements performed, it has been demonstrated that even at a carbon black content of $1 \%$ by weight in the matrix of Mater-Bi EF51L and HF03A2, a sharp increase in electrical conductivity can be detected. Comparing the electroconductivity results obtained in this study with those reported earlier for PLA/MWCNTs, ${ }^{11}$ materials containing carbon black seem to be very good conductors. The electrical conductivity of Mater-Bi composites filled with carbon black is a few times higher than that of composites based on PLA with nanotubes incorporated. The electroconductive filler presented in this work dispersed very well in both matrices, allowing the formation of continuous conductive paths in them. Thus, the percolation threshold of the tested materials has been set to $1 \mathrm{wt} \%$ of CB. However, further and more detailed measurements should be performed.

\section{CONCLUSION}

The obtained results demonstrated that soot/Mater-Bi biodegradable materials present electroconductive properties. Our data evidenced that the formation of carbon black agglomerates did not exert any negative effects on the creation of a scroll path. It was found that $1 \%$ by weight of carbon black in the material gives the most desirable results, because it causes a slight deterioration of the mechanical properties of the tested composites, while achieving very good conductive properties.
Several strategies could be used to further control the final properties of conducting materials. Thus, Mater-Bi can be chosen as matrix to obtain materials with very good conductivity, without much sacrifice in mechanical properties.

\section{REFERENCES}

1 Bioplastics, bioplastics.org/bioplastics/

2 S. Jacukiewicz, Opakowanie, 8, 49 (2002), http://sigma-not.pl/czasopisma-42-czasopismawielobranzowe-opakowanie.html

3 PlasticsEurope, https://www.plasticseurope.org/pl/aboutplastics/packaging

4 Lepitreb: Mater-Bi ${ }^{\circledR} \quad$ Biopolymers, https://bioplasticsnews.com/2013/12/30/mater-bibiopolymers/

5 B. Oh and and P. George, Brain Res. Bull., 148, 10 (2019), https://doi.org/10.1016/j.brainresbull.2019.02.015

6 G. Moro, F. Bottari, N. Sleegers, A. Florea, T. Cowen et al., Sens. Actuat. B Chem., 297, 126786 (2019), https://doi.org/10.1016/j.snb.2019.126786

R.-Q. Zhang, L.-B. Wang, R.-X. Bai, Y.-L. Luo, F. Xu et al., Compos. Part B Eng., 173, 106894 (2019), https://doi.org/10.1016/j.compositesb.2019.05.105

${ }^{8}$ K. Wu, Y. Xue, W. Yang, S. Chai, F. Chen et al., Compos. Sci. Technol., 130, 28 (2016), https://doi.org/10.1016/j.compscitech.2016.04.034

9 B. Tylkowski, K. Wieszczycka and R. Jastrzab, "Polymer Engineering", Walter de Gruyter GmbH \& Co KG (2017), https://www.degruyter.com/view/product/468928 


\section{ANDRZEJ IWAŃCZUK and MARTYNA WALKÓW}

10 Rutalia Masterbatches \& Additives, http://www.rutalia.com/oferta/sadza-techniczna

11 H. Quan, S. Zhang, J. Qiao and L. Zhang, Polymer, 53, 4547

(2012),

https://doi.org/10.1016/j.polymer.2012.07.061

12 W. Zhai, S. Zhao, Y. Wang, G. Zheng, K. Dai et al., Compos. Part A, Appl. Sci. Manuf., 105, 68 (2018), https://doi.org/10.1016/j.compositesa.2017.11.008 